\title{
Pioneer in Subjective Quality of Life Research: Willem Saris
}

\section{Ruut Veenhoven ${ }^{1}$}

Published online: 6 May 2021

(C) The International Society for Quality-of-Life Studies (ISQOLS) and Springer Nature B.V. 2021

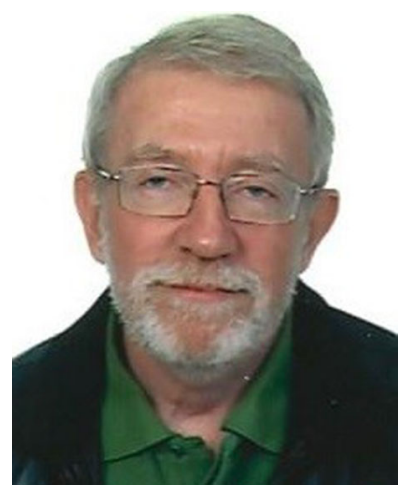

In 1995 I got a telephone call from Willem Saris. I knew him by name, but we had never met. I worked at Erasmus University Rotterdam and Willem at the University of Amsterdam, which are different worlds even in a small land like the Netherlands. Willem told me that he was preparing an edited book on life satisfaction in a crosscultural perspective and needed an introductory chapter by a specialist. Initially, American pioneer in satisfaction research Frank Andrews had agreed to write that chapter, but his untimely death prevented this. So, Willem went local and asked me to step in. I accepted his invitation, feeling honored to follow in the footsteps of Frank Andrews. This was the beginning of our fruitful cooperation and a personal friendship.

Our first project was the book "A comparative study of satisfaction with life in Europe" to which I contributed several chapters and together with Willem the chapter 'Satisfaction in 10 countries, Summary of findings'. The book was ahead of its time, in particular with respect to its methodological chapters.

Ruut Veenhoven

veenhoven@ese.eur.nl

1 Erasmus Happiness Economics Research Organization EHERO, Erasmus University Rotterdam, Rotterdam, Netherlands 
The next step in our cooperation came when I tried to assess the truth to be found in two competing theories of happiness, one view holding that life-satisfaction depends on living conditions and varies with the quality of these (livability theory), while the other view holds that life-satisfaction is a fixed mental trait that tends to remain unchanged in good or bad conditions (set-point theory). The first theory predicts that happiness will change over time, in particular when life-situations change, while the second holds that happiness will at best oscillate a bit around a stable level.

I had started an analysis of the German Socio-Economic Panel study, which by that time provided 10-year yearly follow-up data on a large sample of the general population in Germany. I did this study together with Joop Ehrhardt, a retired physicist who had joined my research group as a volunteer. We soon discovered that our methodological expertise felt short and I asked Willem Saris for advice. Willem helped us out. We found that individual's year-to-year stability of happiness tends to be high, but that over a 10-year period much of the initial rank-order of happiness had evaporated. Willem decomposed the variance in: 1) error components, 2) a learning effect, 3) an ageing effect and 4) actual changes in living conditions, the latter accounting for some $60 \%$ of the variance and as such supporting livability theory. Together we wrote the paper Stability of life-satisfaction over time: Analysis of change in ranks in a national population, which was published in the first volume off the Journal of Happiness Studies and is well cited.

Willem also helped me answer the related question of whether Russian unhappiness is a reflection of their poor living conditions, or rather a cultural tendency to see the glass half empty. Willem provided me with two Russian datasets, the analysis of which resulted in the paper 'Are the Russians as unhappy as they say they are? We found no indications of massive distortion in answers to questions in life-satisfaction and the considerable decline of life-satisfaction during the hectic 10 years after the fall of communism did not suggest that answers were guided by a fixed disposition. Given this evidence for the livability theory, I predicted that "Russian happiness will rise to the level of the early 1980s, once the economic situation has stabilized, and grow to higher levels than before when the advantages of newly acquired wealth and freedom are reaped." This has happened; average happiness in Russia rose by about $10 \%$ in the years after 2000 .

In the same issue of the Journal of Happiness Studies, Willem Saris published the article 'What influences subjective wellbeing in Russia?' which revealed substantial differences with earlier studies in western nations.

Independently, we both addressed the relationship between satisfaction with life-asa-whole and satisfaction with life-domains, such as the satisfaction with one's marriage and with one's job. The dominant view in the 1990s was that in assessing our satisfaction with our life-as-a-whole, we sum our satisfaction with life-domains. Together with Bruce Headey and Alex Wearing, I challenged this 'bottom-up' theory. In a cross-lagged analysis of Australian panel data we showed strong 'top-down' effects of satisfaction with life-as-a-whole on satisfaction with domains of life. In the case of satisfaction with work, the top-down effects appeared to be stronger than the bottom-up effects, while in the case of satisfaction with marriage the effects were about equally strong. See 'Top-down versus bottom-up theories of subjective wellbeing'. The strong top-down effect in how we assess how satisfied we are with our job has been reproduced in several later studies. A practical consequence of this finding is that the 
raising job-satisfaction (and hence productivity) requires more than better work conditions but also requires boosting wider life-satisfaction; a consequence which is not well acknowledged by the current "worker-happiness" industry.

Willem Saris has enriched this strand of research by revealing moderators in these relationships. Together with Annette Scherpenzeel, he has shown that for high-income people satisfaction with social contacts has a bottom-up effect but satisfaction with income a top down effect, while for poor people it is the other way around. This is shown in the paper 'Causal direction in a model of life-satisfaction: The top-down/ bottom-up controversy', which otherwise revealed much contextual variation.

Willem was also a pioneer with respect to the relationship between income and lifesatisfaction. Normally the same-time relationship is rather low but when he considered the effect of change in income on the change in life-satisfaction he obtained a much higher explained variances for the same variables. See "The relationship between income and satisfaction: The effect of measurement error and suppressor variables".

Our last professional meeting was in Barcelona, where I served on the dissertation committee of Willem's PhD student André Pirralha. We also met at conferences in different parts of the world and had satisfying conversations over a satisfying drink.

More detail about Willen Saris is found on https://en.wikipedia.org/wiki/ Willem_Saris

A professional auto-biography of Willem and his wife Irmtraud is available at https://decisions-saris-gallhofer.weebly.com/

Publisher's Note Springer Nature remains neutral with regard to jurisdictional claims in published maps and institutional affiliations. 